\title{
Amenorrhœa, Associated with Serious Eye Symptoms in a Young Girl.
}

By J. E. Gemment, M.B., Hon. Surgeon to the Hospital for Women; and to the Lying-in Hospital, Liverpool; Hon. Gyncecologist, Victoria Central Hospital, Liscard.

ON January 3rd, 1904, Mr. Bickerton, ophthalmic surgeon, asked me to see a young lady in consultation with him, who was suffering from hæmorrhages in both eyes, associated with amenorrhœa; and to advise as to the means of re-establishing menstruation.

The patient was a schoolgirl, æt. 16, who gave the following history:-Menstruation occurred normally from September 19th to 27th, 1903. On September 23rd she travelled from North Wales to Arnside for the purpose of entering a ladies' boarding school, this being her first term away from home. Menstruation has not taken place since, but about the end of October (i.e., about the next menstrual period), whilst at her drawing-class, she found she was blind in the right eye, but could see quite well with the left eye. The condition was noted, but nothing was done until she came home for the Xmas holidays, when her parents took alarm at the blindness.

Mir. Bickerton saw her on December 31st, and reported:-Right vision nil. Doubtful if she can even detect light. Right fundal reflex nil, except at the upper and inner quadrant, where there is a small triangular space of fundal reflex. Left vision, ${ }^{62} / 24,{ }^{6} /{ }_{18}$, perfectly, ${ }^{6} / 12$ one. Jaegar 1 at 15 inches. In the left eye is seen a faint floating vitreous cloud.

Menstrual history. Commenced at 13; regular 28-day type; usually four days, up to September 19th, 1903, since which time amenorrhœa. The last menstrual period was prolonged to eight days, and occurred at the time she had to travel North. At the same time, it may be noted, she goes to a new school, is amongst strangers, and for the first time in her life alone and away from home.

General history. Her general health is good, there is no anæmia, chlorosis, or constipation. She is well nourished and of a rosy complexion; the appetite is good, and she has had plenty of good, wholesome food, made up of a mixed diet. The blood has been examined by Dr. Warrington and found normal in all respects. Urine normal. There is no vaginal discharge of any description, no complaint of pelvic disorder, no symptom of menstrual molimina. She has taken a good place in the school, but has had to work hard. Exercise has been a boarding-school walk and calisthenics. 
With such a history it will be observed there is an absence of the more usual causes of amenorrhœa, excepting those of climatic change, increased mental activity (under competition), and insufficient outdoor exercise. It is not uncommon to find amenorrhœe under similar circumstances; very frequently it occurs in young ladies going to school in Belguim, France and Germany; most probably due to the change of diet, and not giving rise to symptoms other than those of lassitude and headache, it is consequently not regarded as of much moment; but if such a serious complication as blindness may be a result, then the subject is one worthy of consideration and closer attention. Why should such conditions produce amenorrhœa? and why should amenorrhœa be associated with hæmorrhages into the vitreous?

In looking up the literature of such cases in gynæcological works, under the heading of "Amenorrhœea, Symptoms, Treatment, \&c.," I find no allusion to eye symptoms, except by Pozzi, who states that "certain sensorial disorders, such as weakness of sight, \&c., may appear," and refers to the works of Abadie and Mooren for further information.

We know very well that the generative system is so intimately related to the whole organism as to exert an influence such as is not seen in the case of any other system. We also know that irritation of any sensory nerve has a reflex action upon other nerves, either of a similar or different function, and through the vaso-motor system its influence may be exerted upon blood-vessels, the most distant from the point where the disordered action began. Thus the complex nervous connections of the uterus and ovaries, through the splancbnic system, render reflex disturbances in such distant parts as the eye, as a result of irritation, very possible.

Further, the whole system sympathises with the development of the menstrual discharge, and every ophthalmic work refers to eye changes associated with the reproductive system and with menstrual disorders.

Many illustrations are quoted of inflammatory conditions of cornea and sclerotic getting well in the inter-menstrual period and recurring with the onset of menstruation.

In the early stages of renal disease, hæmorrhages are apt to occur in the retina, resulting from the absorption of toxins, and independent of those due to vascular changes, which occur later; so it is possible that we may have an analagous condition here, for with amenorrhea there is an interference with that elimination of toxic substances by the uterus, which is said to occur at each monthly 
period. This may lead to an accumulation of toxins, which will affect the nutritive power of the blood, or act as an irritant to the uterine nerves. Vicarious menstruation is considered to be the cause of these hæmorrhages by the ophthalmic surgeons, and although as a student $I$ was taught to believe that there was no such thing as vicarious menstruation, yet experience has demonstrated various hæmorrhages (epistaxis, hæmoptysis, hæmatemesis) recurring at a menstrual period, and dependent upon that period. Women themselves also believe thoroughly in the occurrence of vicarious menstruation, that belief being based upon the experience of their sex, so that now I am of the opinion that there does occur at times a vicarious menstruation, and that this case belongs to this category.

As to treatment, it is admitted that the first thing to do is to re-establish the menstrual flow, and therefore we preseribed a mixture of iron and aloes, to be taken three times a day, and thyroid tabloids, 5 grs., at bedtime, with the result that menstruation took place again on January 19th.

The local treatment adopted by Mr. Bickerton was rest in bed in a warm room, and leeches occasionally to the temples, and on January 18th his report was: "Left eye perfect; right eye very little. improvement."

The prognosis as regards the eje is not very favourable, but if the menstrual period is not re-established it becomes still more grave, as there may be repeated hæmorrhages into the eye that may cause permanent damage.

\section{REFERENCES.}

Pozzi. Traité de Gynécologie.

Maitland Ramsey. Lancet, 1895. Vol. i., p. 855.

LAWRENCE. (Diseases of the eye.)

Power. Lancet, Nov. 26, 1887, p. 1,051.

Allbutt and Platfair. System of Gynacol., p. 347. 